\title{
Editorial
}

\section{Universidad Peruana Cayetano Heredia: Cumpliendo sesenta años en un mundo convulsionado}

\author{
Universidad Peruana Cayetano Heredia: Turning sixty years old in a troubled world
}

\author{
Carlos F. Cáceres ${ }^{(1)}$
}

Es septiembre de 2021 y la Universidad Peruana Cayetano Heredia cumple sesenta años de fundada. Hablar del sexagésimo aniversario de nuestra alma mater en este editorial de Acta Herediana es un gran honor que, sin embargo, involucra un gran reto: hacer justicia al contexto. No podemos enfocarnos en este aniversario sin dejar de referirnos a las especialísimas circunstancias que vivimos en este momento, tanto dentro del país (Bicentenario de la Independencia en medio de una inédita crisis política), como en el mundo (una tragedia sanitaria global que está produciendo una serie de desequilibrios económicos y políticos, de alcance insospechado, todo lo cual determina una convulsión que no se ha visto tal vez desde la II Guerra Mundial). Esbozaremos los rasgos básicos de esta realidad, y reflexionaremos sobre sus implicancias para nuestra universidad al trasponer la respetable barrera de los sesenta años.

\section{El gran legado de los fundadores}

El camino de la excelencia en la trayectoria de la UPCH fue trazado por sus fundadores, entre los que se cuentan algunos de los más importantes docentes, investigadores, humanistas y profesionales sanitarios de la segunda mitad del siglo XX en el Perú. ${ }^{1}$ Todos

(1) Vicerrector de Investigación, Universidad Peruana Cayetano Heredia, Lima, Perú. ellos construyeron un entorno de trabajo que, por la combinación de talento, mística y sensibilidad social, entre otros valores, resultó extraordinario en el entorno nacional. Tales elementos generaron promociones de profesionales que, ya sea en el país o en otras latitudes, mantienen fuertes vínculos con la alma mater, así como colaboraciones internacionales de docencia e investigación que, con el paso del tiempo, han generado un atractivo entramado para la investigación colaborativa de excelencia y para el intercambio docente-estudiantil, pese a que en las últimas cuatro décadas no hemos recibido apoyo estatal, y tampoco tenemos ni buscamos inversiones con expectativas de lucro. Casi todos nuestros fundadores nos han dejado ya, por lo cual lo que ocurra con este legado en el futuro cercano dependerá en gran medida de nosotros y de las formas en que enfrentemos las complejas realidades que nos toca vivir actualmente. En las siguientes entradas, analicemos ese contexto y su posible impacto sobre la institución, de cara al futuro.

\section{Crisis sanitaria global que ha transformado el mundo}

Al escribir estas líneas, agosto 2021, el mundo es muy distinto de lo que fue hasta marzo de 2020. 
Y pese al año y medio transcurrido, aún no lo terminamos de creer. Una infección viral aparecida en China se expandiría epidémicamente por todas las regiones del mundo. Muchos de los afectados tendrían cuadros severos de insuficiencia respiratoria y no sobrevivirían. La respuesta a la misma sería una cuarentena observada casi globalmente por varias semanas, con cierre de fronteras y del tráfico aéreo. También se impondría el uso de mascarillas y el 'distanciamiento social' en público. ${ }^{2}$

Como era de esperar, el trágico impacto sanitario de la enfermedad se vio acompañado por el enorme efecto económico recesivo de la respuesta a la misma. $^{3}$

Luego de los primeros tres meses, la epidemia de COVID-19 desarrollaría curvas epidémicas diferenciadas por país, en las que 'olas' de distinta magnitud y duración, tanto de casos como de decesos, cederían el paso a períodos de relativa calma, usualmente no muy largos, antes de la aparición de la siguiente 'ola'. En el tiempo, la pandemia iría cambiando su faz debido al surgimiento de 'variantes', enunciadas con letras griegas, presuntamente cada vez más infectantes. ${ }^{4}$ Frente a todo esto, las medidas de control de los países serían variables, generalmente cíclicas en su carácter restrictivo, y en ciertos casos marcadas por el color político, con variada respuesta del público. ${ }^{5}$

Los lineamientos de la respuesta sanitaria global 'oficial' frente a la epidemia han cambiado de forma constante y no han estado libres de críticas que se enfocan, por ejemplo, en: (a) el manejo sesgado hacia la fase grave de COVID-19, de preferencia en una unidad de cuidados intensivos; ${ }^{6}$; (b) el enfoque, desde el inicio de la pandemia, en la vacuna casi como la única solución posible para la misma, y la enorme inversión en vacunas experimentales, sin duda novedosas y prometedoras, pero con pruebas incompletas, que serían aprobadas de emergencia para un programa de vacunación masiva ${ }^{7} ;$ y (c) la controversia sobre el tratamiento temprano, que algunos proponen con el uso redirigido de ciertos medicamentos seguros aprobados para otras indicaciones, mientras otros los critican aduciendo que la evidencia es pobre o insuficiente ${ }^{8}$, y con un tercer grupo que se extraña por el contrasentido. ${ }^{9}$

Nueve meses después de que se iniciara la vacunación en el mundo, las coberturas varían mucho entre países, y se ha reconocido que las vacunas no previenen la infección ni la transmisión del virus, siendo más efectivas en la prevención de enfermedad grave y muerte, sin total claridad sobre su utilidad frente a las nuevas variantes conocidas y por venir. ${ }^{10}$ En algunos países, proporciones no pequeñas de la población desconfían de las vacunas $\mathrm{y}$ protestan frente a las crecientes presiones por hacerlas obligatorias. ${ }^{11}$ La economía mundial no se ha recuperado al nivel deseable; por el contrario, muchas empresas pequeñas cerraron, y los conflictos sociales parecen constituir la norma en el mundo, con creciente preocupación por la seguridad alimentaria. $^{12}$

Esta es, grosso modo, la situación del planeta en el momento actual. Su especial crispación e impredecibilidad constituyen un escenario sombrío y posiblemente riesgoso a nivel internacional, en el que periódicamente emergen crisis como la de Afganistán. ${ }^{13}$

\section{El Perú: Tragedia sanitaria y debacle política en torno al Bicentenario de la Independencia}

Este último 28 de julio el Perú cumplió 200 años de independencia de España, aunque prácticamente no lo celebró. Los motivos fueron principalmente dos. El primero, el enorme impacto del COVID-19 sobre la población del país. Algo más de dos millones de peruanos, un $6 \%$ de la población, habrían tenido resultados positivos, con síntomas o no. ${ }^{14}$ Pero lo más doloroso sería la catastrófica mortalidad por COVID-19 que el Perú ha experimentado ${ }^{(2)}$,

(2) En relación con las muertes por COVID, en abril 2021 se dio un 
generalmente por insuficiencia respiratoria en casos que se complicaron, sin lograr acceder, o a pesar de acceder, a unidades de cuidados intensivos, situación agravada porque muchas de tales muertes ocurrieron sin que hubiera contacto con los familiares, y porque hubo restricciones para velorios y sepelios. ${ }^{15}$

Sin lugar a dudas, el país está muy golpeado por una epidemia en la que no pocos han perdido a un ser querido, o más de uno, y en la que muchos han sufrido el embate del COVID y se recuperan con mayor o menor dificultad. Como país, sin embargo, nos hemos topado con una realidad dura: nuestro sistema de salud tiene grandes deficiencias que reflejan, además, la enorme desigualdad que nos caracteriza. ${ }^{16}$ Durante los últimos meses, aunque el Perú pareció unirse frente a la meta de llevar la vacuna a todos los rincones de nuestra geografía, no han faltado quienes han utilizado el tema para atacar a rivales políticos de forma irresponsable en extremo. ${ }^{17}$

Justamente, el segundo motivo para la frugalidad del bicentenario radicó en la mediocre trama del melodrama político que hemos vivido en los últimos cinco años. En el quinquenio que terminó vimos pasar a cuatro presidentes y dos congresos, con tres presidentes depuestos y un congreso disuelto. ${ }^{18}$ $\mathrm{Y}$, las recientes elecciones, de cara al bicentenario, evidenciaron la atomización de agrupaciones con ambiciones más que ideario, y con agenda de intereses más que programa de gobierno. Al ballotage pasaron dos extremos opuestos, con pobre votación debido a la dispersión del voto entre opciones más centristas;

ejercicio de 'sinceramiento' que las hizo pasar de 65000 a 180000 , estando ya próximas a llegar a 200000 . Si bien todo esfuerzo por la transparencia es meritorio, es importante definir hasta dónde se transparenta la realidad, y dónde se podría comenzar a construir otra fantasía, pues los actuales criterios para el diagnóstico son tan amplios (ver tabla en https://saludconlupa.com/noticias/per-actualizala-cifra-de-muertos-por-covid-19-son-ms-de-180-mil-muertos/) que pueden llevarnos del subregistro al sobre registro. Nos han convertido, de un país con tasas de mortalidad similares a las de Argentina, Brasil y Colombia (2 300-2 600/millón ahora), a ser el país que reporta la mayor mortalidad del mundo (5 893/millón), bastante mayor a la del segundo país, Hungría (3 118/millón). (ver https://www. worldometers.info/coronavirus/). $\mathrm{y}$, vivimos una de las peores campañas electorales de la historia, caracterizada por la incredulidad de muchos y una inédita polarización de los votantes en medio de una lamentable parcialización de todos los grandes medios de comunicación por una candidata que perdería por tercera vez y negándose a aceptar su derrota con el apoyo de todo ese aparato mediático, con una denuncia de fraude electoral teñida de racismo y retrasando la proclamación del ganador hasta nueve días antes del Discurso a la Nación. ${ }^{19}$

Aunque el partido triunfador no es el monstruo comunista que pintó el macartismo de caricatura que lo atacó, sin duda muestra grandes debilidades, desde la ausencia de cuadros propios hasta el ambicioso proyecto político de su líder, que no es el presidente. Este último intenta construir un espacio de autonomía con los apoyos que ha logrado concretar de sectores afines, aunque el camino hacia la consolidación de su naciente gobierno aún está en construcción. ${ }^{20}$ En la celebración del Bicentenario en la Pampa de la Quinua, su origen campesino y rural resultó talvez un símbolo poderoso de la aún utópica inclusión social de un grupo secularmente postergado. Esperemos que algo se avance en esa dirección, al inicio de este tercer siglo de vida independiente de la nación peruana.

\section{Vacunagate: Un complejo entramado ético}

De vuelta a casa, este año hiperrealista ha sido también el de la mayor crisis que se haya vivido en los claustros heredianos. La causa: Vacunagate, el affaire de las vacunas de la 'lista especial' de un ensayo clínico vacunal para COVID-19 que se inició con UPCH como 'patrocinador' y como uno de los centros de investigación, mientras la Universidad Nacional Mayor de San Marcos aportaba el otro. El estudio, propuesto al Perú por el Estado Chino, evaluaría la eficacia y seguridad de dos configuraciones de la vacuna, comparadas con placebo. ${ }^{21}$ Cuando el estudio estaba por iniciarse, la contraparte expresó su disposición a entregar vacunas adicionales "para la protección del equipo", 
oferta que se había materializado en sus estudios en otros países. Aceptada a nivel local, se incluyó en una enmienda al protocolo que pidió estas dosis 'para el equipo de investigación y colaboradores', la cual sería aprobada por el Comité Nacional Transitorio de Ética de Investigación (CNTEI), y tramitada por el Instituto Nacional de Salud (INS) y la Dirección General de Medicamentos, Insumos y Drogas (DIGEMID). Una vez aprobada dicha enmienda, los líderes implementaron la vacunación de su personal y utilizaron un criterio en extremo amplio para definir a los 'colaboradores' del estudio, pues se incluyó a funcionarios del Ministerio de Salud y de la Cancillería, a proveedores comerciales del estudio, e incluso el ex presidente Vizcarra y otros políticos. ${ }^{22}$

Sin evidencia de dolo, la inclusión de Vizcarra generó un escándalo mediático cuando se filtró a la prensa. La situación empeoró cuando los investigadores principales declararon $\sin$ asesoría ante las autoridades, y el caso derivó en investigaciones en varios fueros que tendrían secuelas. Aunque los investigadores fueron separados del estudio $\mathrm{y}$ ahora han sido sancionados tras un debido proceso, ${ }^{23}$ las expectativas sobre el castigo eran diversas, y quienes esperaban una sanción radical expresan su frustración. Desde la UPCH, además de los investigadores del estudio, estuvieron en falta los docentes y funcionarios que se vacunaron, especialmente las autoridades, que renunciaron en su momento, mientras que las varias facultades continúan los procesos éticos contra sus profesores.

No tenemos los elementos para procesar 'Vacunagate' de una forma consensual. A nuestro entender, las razones son varias: (1) diferente entendimiento de la investigación y sus supuestos; (2) diferente valoración del contexto externo: emergencia sanitaria; exclusión del Comité de Ética de UPCH, por norma nacional; manejo 'de alto nivel' de la propuesta; aprobación de enmienda por instancias nacionales; ausencia de dolo; origen político del escándalo; (3) diferente opinión sobre los involucrados. Pero, requerimos darnos tiempo para comprender y procesar esta experiencia, de modo de seguir adelante.

\section{Honrando nuestros sesenta años de cara al futuro}

El recuento planteado arriba tiene el objeto, sin duda inusual, de evidenciar el momento especialmente difícil que viven la universidad, el país y el mundo. Por ello, tal vez resulte hasta extraño hablar de 'celebración' o festejo por este aniversario. Pero lo que sí debemos hacer es honrarlo. Lo honramos recordando esa herencia de los fundadores, ese legado que va mucho más allá del nombre, el local o la institución, y tiene que ver con la historia, los logros y los valores, con ese 'espíritu herediano' que con elocuencia nos recuerda la erudición de don Honorio Delgado al hablarnos de Spiritus ubi vult Spirat. $^{24}$

Lo honramos también comprometiéndonos a aportar en el avance científico mundial de cara a la pandemia, manteniendo un espíritu crítico frente al discurso único, y cultivando una creatividad proactiva para echar a andar proyectos relevantes. A nivel de país, lo hacemos cuestionando que la política pública sea solo la adopción sumisa de prácticas sanitarias recomendadas desde el exterior con menos evidencia de la que se pregona, y fomentando el diálogo alturado frente a la ramplona intolerancia del disenso, en tiempos en los que se manipula con el recurso a la evidencia para imponer la tiranía del dogma.

Honramos este sexagésimo aniversario cuando reconocemos el momento límite que viven el país $\mathrm{y}$ el mundo, y tomamos conciencia de nuestra obligación moral de madurez, de hacerlo mejor, dejando el ego a un lado, cumpliendo compromisos a tiempo, superando las expectativas de los demás. Y lo hacemos también, como comunidad académica frente al Vacunagate, cuando reconocemos en él una expresión de un problema colectivo del que somos parte, y lo abordamos con hidalguía en vez de limitarnos a pedir la cabeza de otros, como si todo 
lo malo fuera externo; cuando comprendemos que, además de ser buenos investigadores, tenemos que ser buenas personas.

Y, el hacer todo esto nos permitirá, tal vez, vivir este aniversario como un hito colectivo, el del paso a la madurez, a la sabiduría de la tercera edad, en cuerpos de todas las edades. Nos dejará, quizás, experimentar el influjo iluminador y redentor del espíritu herediano.

\section{Referencias bibliográficas}

1. Porturas Plaza, Fernando. El origen de la Universidad Peruana Cayetano Heredia. Revista Médica Herediana. 199;10 (4):151-166. URL disponible en: http://www.scielo.org.pe/pdf/rmh/v10n4/v10 n4ce1

2. Yen-Chin Liu, Rei-Lin Kuo, Shin-Ru Shih. COVID-19: The first documented coronavirus pandemic in history. Biomedical Journal. 2020; 43: 328-333. URL disponible en: https://doi.org/10.1016/j. bj.2020.04.007

3. The World Bank. Lights out? Covid-19 containment Policy and Economic Activity. URL disponible en: https://blogs.worldbank. org/developmenttalk/lights-out-covid-19-containment-policies-andeconomic-activity

4. Takahiko Koyama, Dilhan Weeraratne, Jane L. Snowdon, Laxmi Parida. Emergence of drift variants that may affect COVID-19 vaccine development and antibody treatment. Pathogens. 2020, 9(5):324. doi.org/10.3390/pathogens9050324

5. David M. Studdert, Mark A. Hall. disease control, civil liberties, and mass testing - Calibrating restrictions during the COVID-19 pandemic. N Engl J Med. 2020; 383:102-104. DOI: 10.1056/NEJMp2007637.

6. Audrey Giraud-Gatineau, Sébastien Cortaredona, Jean-Christophe Lagier, et al. The need for early management in patients with COVID-19. February 2021 DOI. http://dx.doi.org/10.21203/ rs.3.rs-251817/v1

7. Aaron Wherry. While the nation obsessed over vaccine deliveries, the pandemic was getting worse. CBC News. 13 January 2021. URL disponible en: https://www.cbc.ca/news/politics/vaccine-pandemiccovid-ford-trudeau-kenney-1.5870641

8. Bryant, Andrew; Lawrie, Theresa A.; Dowswell, Therese; Fordham, Edmund J.; Mitchell, Scott,; Hill, Sarah R.; Tham, Tony C. Ivermectin for prevention and treatment of COVID-19 infection: A systematic review, meta-analysis, and trial sequential analysis to inform clinical guidelines. American Journal of Therapeutics. July/August 2021;28(4):e434-e460 doi: 0.1097/MJT.0000000000001402.

9. The Wall Street Journal: Why is the FDA attacking a safe, effective drug? 28 July 2021. URL disponible en: https://www.wsj.com/articles/ fda-ivermectin-covid-19-coronavirus-masks-anti-science11627482393

10. Kasen K. Riemersma, Brittany E. Grogan, Amanda Kita-Yarbro, Peter Halfmann, Anna Kocharian, Kelsey R. Florek, et al. Shedding of infectious SARS-CoV-2 despite vaccination when the delta variant is prevalent - Wisconsin, July 2021. doi: https://doi.org/10.1101/2021 .07 .31 .21261387

11. Deutsche Welle. Coronavirus: Thousands protest against restrictions across Europe. 24 July 2021. URL disponible en: https://www. dw.com/en/coronavirus-thousands-protest-against-restrictionsacross-europe/a-58627841

12. The World Bank. Food Security and COVID-19. 17 August 2021. URL disponible en: https://www.worldbank.org/en/topic/agriculture/ brief/food-security-and-covid-19

13. BBC News Mundo. Afganistán: las fechas clave de un conflicto de 20 años. 17 agosto 2021. URL disponible en: https://www.bbc.com/ mundo/noticias-internacional-58239266

14, Ver conteo diario en https://www.worldometers.info/coronavirus/.

15. Salud con Lupa. El dolor dos veces: ¿cómo despedir a nuestros muertos en una pandemia? 14 abril 2020. URL disponible en: https:// saludconlupa.com/noticias/el-dolor-dos-veces-como-despedir-anuestros-muertos-en-una-pandemia/

16. Mujica O. Desigualdades sociales en la mortalidad durante la COVID-19 en Lima y Callao. Rev Per med exp salud publica. 2021;38(1). Epub 27-Ene-2021. URL disponible en: http://dx.doi. org/10.17843/rpmesp.2021.381.6740

17. Rosas Yasmin. Sinopharm: cuatro testimonios en defensa de una vacuna que salva vidas. El Comercio, 8 agosto 2021. URL disponible en: https://elcomercio.pe/lima/sucesos/sinopharm-cuatro-testimoniosen-defensa-de-una-vacuna-que-salva-vidas-coronavirus-en-perucovid-19-vacunas-minsa-noticia/

18. Agenda Pública. Perú: ¿Cuatro presidentes en cinco años? 10 noviembre 2021. URL disponible en: https://agendapublica.es/perucuatro-presidentes-en-cinco-anos/

19. Milenio. Keiko Fujimori acepta derrota en elección presidencial de Perú, pero llama a movilización. 19 julio 2021. URL disponible en: $\quad$ https://www.milenio.com/internacional/latinoamerica/keikofujimori-reconocera-resultados-elecciones-peru

20. Deutsche Welle. Perú: confrontación marca inicio del Gobierno de Pedro Castillo. 10 agosto 2021. URL disponible en: https://www. dw.com/es/per\%C3\%BA-confrontaci $\% \mathrm{C} 3 \% \mathrm{~B} 3 n$-marca-inicio-delgobierno-de-pedro-castillo/a-58818858

21. Ministerio de Relaciones Exteriores. Laboratorio chino Sinopharm llega al Perú con las pruebas para el ensayo clínico Fase III de la vacuna contra el Covid-19. 2 septiembre 2020. URL disponible en: https://www.gob.pe/institucion/rree/noticias/297538-laboratoriochino-sinopharm-llega-al-peru-con-las-pruebas-para-el-ensayoclinico-fase-iii-de-la-vacuna-contra-el-covid-19

22. Ministerio de Salud. Informe de la comisión sectorial investigadora de la aplicación de la vacuna candidata contra la COVID-19. 25 febrero 2021. URL disponible en: https://www.gob.pe/institucion/ minsa/informes-publicaciones/1721531-informe-de-la-comisionsectorial-investigadora-de-la-aplicacion-de-la-vacuna-candidatacontra-la-covid-19

23. El Comercio. Vacunagate: Germán Málaga fue sancionado con separación por un año de la Universidad Cayetano Heredia. 15 julio 2021. URL disponible en: https://elcomercio.pe/lima/ vacunagate-universidad-peruana-cayetano-heredia-sanciona-aresponsables-del-ensayo-clinico-sinopharm-covid-19-vacuna-covid19-coronavirus-nndc-noticia/

24. Porturas, Fernando. Origen de la Universidad Peruana Cayetano Heredia, Revista Medica Herediana: Vol. 10 Núm. 4 (1999): octubre - diciembre. Disponible en: https://revistas.upch.edu.pe/index.php/ RMH/article/view/618

\section{Correspondencia:}

\author{
Carlos F. Cáceres \\ carlos.caceres@upch.pe
}

